\title{
King's Brief Interstitial Lung Disease questionnaire: responsiveness and minimum clinically important difference
}

\author{
Claire M. Nolan ${ }^{1,2}$, Surinder S. Birring ${ }^{3}$, Matthew Maddocks ${ }^{4}$, Toby M. Maher ${ }^{5,6}$, \\ Suhani Patel ${ }^{1}$, Ruth E. Barker ${ }^{1,5}$, Sarah E. Jones ${ }^{1,5}$, Jessica A. Walsh ${ }^{1,2}$, \\ Stephanie C. Wynne ${ }^{1}$, Peter M. George ${ }^{5,6}$ and William D-C. Man ${ }^{1,2,5}$
}

Affiliations: ${ }^{1}$ Harefield Pulmonary Rehabilitation and Muscle Research Laboratory, Royal Brompton and Harefield NHS Foundation Trust, Harefield, UK. ${ }^{2}$ Harefield Pulmonary Rehabilitation Unit, Royal Brompton and Harefield NHS Foundation Trust, Harefield, UK. ${ }^{3}$ Centre for Human and Applied Physiological Sciences, School of Basic and Medical Biosciences, Faculty of Life Sciences and Medicine, King's College London, London, UK. ${ }^{4}$ Division of Palliative Care, Policy and Rehabilitation, Cicely Saunders Institute, King's College London, London, UK. ${ }^{5}$ National Heart and Lung Institute, Imperial College London, London, UK. ${ }^{6}$ Interstitial Lung Disease Unit, Royal Brompton and Harefield NHS Foundation Trust, London, UK.

Correspondence: Claire M. Nolan, Harefield Pulmonary Rehabilitation and Muscle Research Laboratory, Royal Brompton and Harefield NHS Foundation Trust, Harefield Hospital, Harefield, UB9 6JH, UK.

E-mail: c.nolanarbht.nhs.uk

@ERSpublications

The King's Brief Interstitial Lung Disease (KBILD) questionnaire is responsive to pulmonary rehabilitation in patients with ILD, including those with IPF, with a mean minimum clinically important difference of 3.9 points for KBILD-Total score http://bit.ly/2HXxBIe

Cite this article as: Nolan CM, Birring SS, Maddocks M, et al. King's Brief Interstitial Lung Disease questionnaire: responsiveness and minimum clinically important difference. Eur Respir J 2019; 54: 1900281 [https://doi.org/10.1183/13993003.00281-2019].

ABSTRACT Health status is increasingly used in clinical practice to quantify symptom burden and as a clinical trial end-point in patients with interstitial lung disease (ILD). The King's Brief Interstitial Lung Disease (KBILD) questionnaire is a brief, validated 15-item, disease-specific, health-related quality of life questionnaire that is increasingly used in clinical trials, but little data exist regarding the minimum clinically important difference (MCID). Using pulmonary rehabilitation as a model, we aimed to determine the responsiveness of KBILD and provide estimates of the MCID.

KBILD scores, Chronic Respiratory Questionnaire (CRQ) scores, Medical Research Council (MRC) Dyspnoea score and incremental shuttle walk test (ISWT) distance were measured in 209 patients with ILD (105 with idiopathic pulmonary fibrosis (IPF)) before and after an outpatient pulmonary rehabilitation programme. Changes with intervention and Cohen's effect size were calculated. Anchor-based (linear regression and receiver operating characteristic plots) or distribution-based approaches ( $0.5 \mathrm{SD}$ and standard error of measurement) were used to estimate the MCID of KBILD domain and total scores.

KBILD, CRQ, MRC Dyspnoea and ISWT improved with intervention, and the effect sizes of KBILD domain and total scores ranged from 0.28 to 0.38 . Using anchor-based estimates, the MCID estimates for KBILD-Psychological, KBILD-Breathlessness and activities, and KBILD-Total were 5.4, 4.4 and 3.9 points, respectively. Using distribution-based methods, the MCID estimate for KBILD-Chest symptoms was 9.8 points. The MCID estimates for KBILD in IPF patients were similar.

In patients with ILD and IPF, KBILD is responsive to intervention with an estimated MCID of 3.9 points for the total score.

This article has supplementary material available from erj.ersjournals.com

Received: 08 Feb 2019 | Accepted after revision: 29 May 2019

Copyright CERS 2019. This article is open access and distributed under the terms of the Creative Commons Attribution Licence 4.0. 


\section{Introduction}

Health status is an important patient-reported outcome measure (PROM) that is increasingly used in clinical practice to quantify symptom burden $[1,2]$ and as a clinical trial end-point in patients with interstitial lung disease (ILD) [1-3]. Pulmonary rehabilitation, a multidisciplinary programme incorporating exercise training and education, is recommended for the management of ILD patients $[2,4]$ as it improves, among other outcomes, health status [5]. However, there is a paucity of data on the responsiveness of ILD-specific health status questionnaires to pulmonary rehabilitation. Currently, ILD patients undergoing pulmonary rehabilitation in research studies and clinical practice are often assessed using generic or disease-specific health status measures for chronic obstructive pulmonary disease (COPD), such as the Short-Form 36 (SF-36) [6, 7], St George's Respiratory Questionnaire (SGRQ) [3, 8-11] or Chronic Respiratory Questionnaire (CRQ) [10, 12, 13].

The King's Brief Interstitial Lung Disease (KBILD) questionnaire is a self-administered, ILD-specific measure of health-related quality of life, comprising 15 items with three domains (Psychological (KBILD-P), Breathlessness and activities (KBILD-B), and Chest symptoms (KBILD-C)) combined in a total score (KBILD-T). Each domain score and the total score ranges from 0 to 100, with higher scores indicating better health-related quality of life. KBILD takes 5-7 min to complete [14], and has been shown to be valid [14, 15], reproducible [14] and responsive to natural longitudinal change [15]. The minimum clinically important difference (MCID) of longitudinal change in KBILD-T in ILD patients (including those with idiopathic pulmonary fibrosis (IPF)) has been estimated at 8 points [15]. Two generations of the questionnaire have been developed, one using Rasch analysis methodology (KBILD-R) [14] and the other using an impact factor technique (KBILD-I) [16], in order to determine whether the clinical properties of the two questionnaires developed using different methodologies were similar. The questionnaires have slightly different content but yield similar results [16]. KBILD-R was used in this study as KBILD-I has not been released for use.

Responsiveness of KBILD to pulmonary rehabilitation has not been previously reported. Furthermore, although it is increasingly used as a trial end-point in ILD patients [3], the MCID in response to intervention is unknown. Accordingly, the aims of this study were to determine the responsiveness of KBILD domain and total scores to pulmonary rehabilitation, and to provide estimates of the MCID to intervention. We hypothesised that KBILD would improve with pulmonary rehabilitation and that estimates of MCID response to intervention would be similar to estimates of the MCID of KBILD to longitudinal change.

\section{Materials and methods}

Study subjects

Participants were prospectively recruited from two cohorts undergoing pulmonary rehabilitation to determine the responsiveness of physical performance measures (ClinicalTrials.gov identifiers NCT02530736 and NCT01649193) between March 2012 and July 2016. Inclusion criteria for this study were: 1) a primary diagnosis of an ILD, according to a specialist respiratory physician and a positive radiological diagnosis by high-resolution computed tomography scan following multidisciplinary input, 2) ability to walk $5 \mathrm{~m}, 3$ ) ability to provide informed consent and 4) sufficient understanding of English to complete a health status questionnaire. Exclusion criteria were significant comorbidities that would limit walking ability (e.g. lower limb amputation) or make exercise unsafe (e.g. unstable ischaemic heart disease).

All participants provided informed consent. The study was approved by the London-Riverside (14/LO/ 2247) and London-Camberwell St Giles (11/LO/1780) Research Ethics Committees.

\section{Study design}

The objective of this prospective cohort study was to determine the responsiveness of KBILD domain and total scores to pulmonary rehabilitation in patients with ILD, and to provide estimates of the MCID to intervention. Regarding the sample size calculation, for anchor-based approaches of determining the MCID, a minimum correlation $r>0.3$ between the outcome of interest and external anchor is required [17]. To show a correlation of $r>0.3$ between change in KBILD and change in CRQ or ISWT with 95\% power at the 0.05 significance level would require a minimum of 138 patients completing pulmonary rehabilitation. Assuming $30 \%$ of patients would not complete pulmonary rehabilitation [18], we aimed to recruit 200 patients.

\section{Methods}

Pulmonary rehabilitation was delivered by the Harefield Pulmonary Rehabilitation Unit (Harefield, UK), and comprised an 8-week outpatient exercise and multidisciplinary education programme, organised and 
delivered according to the British Thoracic Society Quality Standards for Pulmonary Rehabilitation [19]. Each week involved two supervised sessions of exercise and education, and at least one additional home-based unsupervised exercise session. Details of the exercise and education components have been previously described [20]. The following outcome measures were assessed before and after pulmonary rehabilitation: anthropometry, spirometry [21], Medical Research Council (MRC) Dyspnoea score [22], incremental shuttle walk test (ISWT) distance [23], KBILD scores [14] and self-reported CRQ scores [24].

\section{Statistical analysis}

Baseline characteristics are presented as mean with standard deviation and percentage for continuous and categorical data, respectively. Paired t-tests were used to compare outcomes before and after pulmonary rehabilitation, and effect sizes were calculated using Cohen's $d$ effect size. The association between change in KBILD with change in other outcomes (CRQ, MRC Dyspnoea and ISWT) was determined using Pearson's correlation or Spearman rank correlation.

\section{MCID analysis}

Multiple anchor-based approaches were used to estimate the MCID of KBILD domain and total scores. The a priori criteria for establishing the validity of external anchors were: statistically significant correlation at the 5\% level and $r>0.3$ [17]. For external anchors fulfilling these criteria, linear regression was used to estimate change in KBILD corresponding to the established MCID for the anchors [25]: CRQ-Dyspnoea 2.5 points, CRQ-Fatigue 2 points, CRQ-Emotion 3.5 points, CRQ-Mastery 2 points, CRQ-Total 10 points [26] and ISWT $44 \mathrm{~m}$ [23]. Additionally, receiver operating characteristic (ROC) curves were used to determine change in KBILD cut-off with equal sensitivity and specificity to discriminate between those who improved their external anchor by the established MCID and those who did not [27]. If a potential anchor did not meet the a priori criteria for establishing validity of an external anchor, distribution-based methods were used to estimate the MCID. These included $0.5 \mathrm{SD}$ and standard error of measurement ( $\mathrm{SD}$ of $\mathrm{KBILD} \times \sqrt{ }(1$-test-retest reliability of KBILD)). In pre-specified sensitivity analyses, the response of KBILD to pulmonary rehabilitation was evaluated in the subgroup of IPF patients. Data analyses were performed using Prism version 7 (GraphPad, La Jolla, CA, USA) and SPSS version 24 (IBM, Armonk, NY, USA). Statistical significance was considered at $\mathrm{p}<0.05$.

\section{Results}

Baseline characteristics and response to pulmonary rehabilitation in patients with ILD

A total of 297 consecutive patients referred to the Harefield Pulmonary Rehabilitation Unit were invited to participate in the study: 20 declined, 10 did not meet the inclusion criteria $(n=4$ chose an unsupervised home exercise programme, $n=2$ unstable cardiac condition, $n=2$ foot-drop and $n=2$ unable to walk $5 \mathrm{~m}$ ) with 267 agreeing to participate. A total of 209 (78\%) completed pulmonary rehabilitation. The reasons for noncompletion were: $n=28$ unable to contact, $n=7$ admitted to hospital, $n=3$ converted to a home exercise programme, $\mathrm{n}=2$ cardiac symptoms and $\mathrm{n}=18$ other reason.

Table 1 lists the ILD diagnosis categories and the number of patients in each category; the most common diagnosis was IPF (50\%). The baseline characteristics and the response to pulmonary rehabilitation of the 209 patients who completed the programme are shown in table 2 . The majority of patients were male

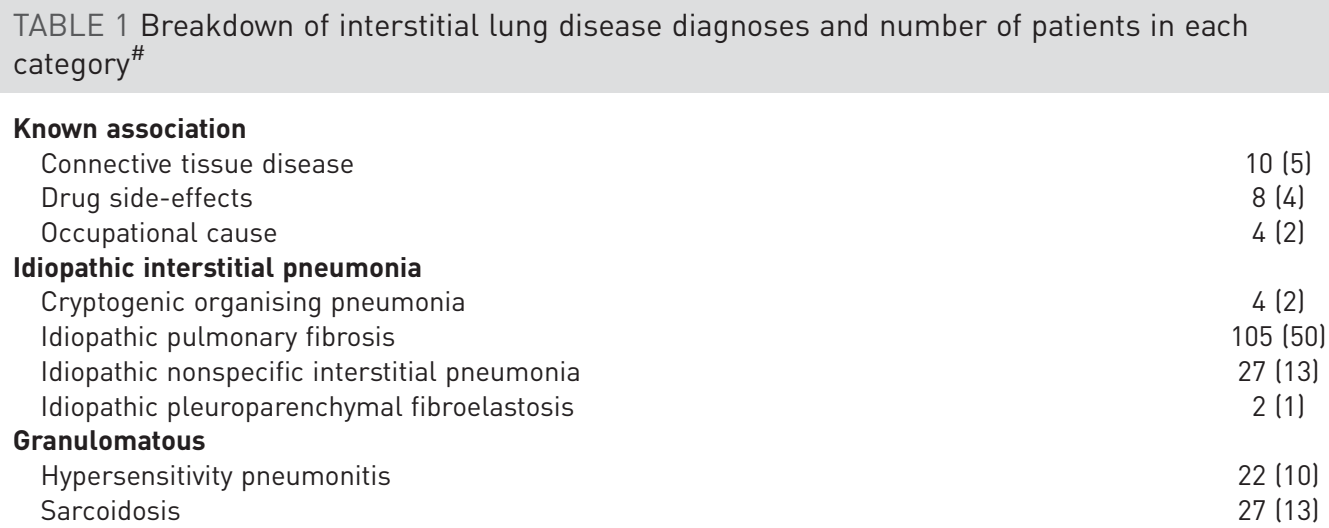

Data are presented as $\mathrm{n}(\%) .{ }^{\#}: \mathrm{n}=209$. 


\begin{tabular}{|c|c|c|c|}
\hline & Baseline & $\begin{array}{l}\text { Response to pulmonary } \\
\text { rehabilitation }(95 \% \mathrm{CI})^{\pi}\end{array}$ & p-value \\
\hline Male & 61 & & \\
\hline Age years & $70 \pm 10$ & & \\
\hline FVC L & $2.2 \pm 0.8$ & $0.0(-0.1-0.0)$ & 0.06 \\
\hline FVC \% pred & $71.9 \pm 21.5$ & $-1.1(-2.9-0.7)$ & 0.22 \\
\hline MRC Dyspnoea score & $3.2 \pm 1.1$ & $-0.7(-0.8--0.5)$ & $<0.01$ \\
\hline BMI $\mathrm{kg} \cdot \mathrm{m}^{-2}$ & $28.5 \pm 6.0$ & $0.0(-0.1-0.1)$ & 0.51 \\
\hline \multicolumn{4}{|l|}{ Smoking status } \\
\hline Never-smoker & 54 & & \\
\hline Current smoker & 2 & & \\
\hline Ex-smoker & 44 & & \\
\hline \multicolumn{4}{|l|}{ Oxygen } \\
\hline Long-term oxygen therapy & 7 & & \\
\hline Ambulatory oxygen therapy & 14 & & \\
\hline ISWT distance $\mathrm{m}$ & $276 \pm 164$ & $63(52-74)$ & $<0.01$ \\
\hline \multicolumn{4}{|l|}{ KBILD score } \\
\hline KBILD-Psychological & $55.7 \pm 16.1$ & $5.9(4.1-7.8)$ & $<0.01$ \\
\hline KBILD-Breathlessness and activities & $39.2 \pm 15.8$ & $5.7(4.0-7.4)$ & $<0.01$ \\
\hline KBILD-Chest symptoms & $62.7 \pm 22.4$ & $6.0(3.5-8.4)$ & $<0.01$ \\
\hline KBILD-Total & $54.3 \pm 10.8$ & $4.2(3.0-5.3)$ & $<0.01$ \\
\hline \multicolumn{4}{|l|}{ CRQ score } \\
\hline CRQ-Dyspnoea & $15.3 \pm 5.5$ & $4.7(3.9-5.4)$ & $<0.01$ \\
\hline CRQ-Fatigue & $14.4 \pm 5.1$ & $2.3(1.7-5.8)$ & $<0.01$ \\
\hline CRQ-Emotion & $31.6 \pm 9.1$ & $3.2(2.3-4.2)$ & $<0.01$ \\
\hline CRQ-Mastery & $18.6 \pm 5.4$ & $1.8(1.2-2.4)$ & $<0.01$ \\
\hline CRQ-Total & $80.0 \pm 20.7$ & $12.0(9.8-14.2)$ & $<0.01$ \\
\hline
\end{tabular}

Baseline data are reported as $\%$ or mean \pm SD, unless otherwise stated. FVC: forced vital capacity; MRC: Medical Research Council; BMI: body mass index; ISWT: incremental shuttle walk test; KBILD: King's Brief Interstitial Lung Disease; CRQ: Chronic Respiratory Questionnaire. \#: $\mathrm{n}=209$; ๆ: a positive change in ISWT, KBILD (domain and total scores) and CRQ (domain and total scores) is associated with improvement, whereas a negative change in MRC Dyspnoea is associated with improvement.

(61\%) with mean \pm SD age $70 \pm 10$ years, forced vital capacity (FVC) $71.9 \pm 21.5 \%$ predicted, MRC Dyspnoea score $3.2 \pm 1.1$ and KBILD-T score $54.3 \pm 10.8$.

MRC Dyspnoea, ISWT and CRQ all significantly improved with pulmonary rehabilitation, as did KBILD domain and total scores. Mean change in score: KBILD-P 5.9 (95\% CI 4.1-7.8), KBILD-B 5.7 (95\% CI 4.0-7.4), KBILD-C 6.0 (95\% CI 3.5-8.4) and KBILD-T 4.2 (95\% CI 3.0-5.3) (table 2). Effect sizes for KBILD-P, KBILD-B, KBILD-C and KBILD-T with pulmonary rehabilitation were $0.34,0.36,0.28$ and 0.38 , respectively.

Estimation of the MCID of KBILD in patients with ILD

Table 3 shows the correlations between KBILD change and change in CRQ, MRC Dyspnoea and ISWT. The CRQ-Total score correlated best with all KBILD domain and total scores.

Using linear regression and ROC plots, the mean MCID estimates for KBILD in patients with ILD were: KBILD-P 5.4 points, KBILD-B 4.4 points and KBILD-T 3.9 points. It was not possible to calculate an anchor-based MCID estimate for KBILD-C as it did not meet the a priori criteria for establishing a valid external anchor (i.e. statistically significant correlation with $r>0.30$ between KBILD-C and an external anchor). Using distribution-based methods, the mean MCID estimate for this domain was 9.8 points. The ranges of MCID estimates for KBILD domain and total scores are shown in table 4.

Responsiveness of KBILD and estimation of the MCID in patients with IPF

A sensitivity analysis was performed to determine the responsiveness of KBILD domain and total scores and estimate an MCID in patients with IPF $(n=104)$. The baseline characteristics and response to pulmonary rehabilitation are shown in supplementary table S1. In summary, 69\% of patients were male with mean \pm SD age $73 \pm 8$ years, FVC $74.4 \pm 21.4 \%$ predicted, MRC Dyspnoea score $3.1 \pm 1.1$ and KBILD-T 
TABLE 3 Correlations between change $(\Delta)$ in King's Brief Interstitial Lung Disease (KBILD) and change in other variables with pulmonary rehabilitation in patients with interstitial lung disease

\begin{tabular}{|c|c|c|c|c|}
\hline & $\Delta$ KBILD-P & $\Delta$ KBILD-B & $\Delta$ KBILD-C & $\Delta$ KBILD-T \\
\hline$\Delta \mathrm{MRC}$ Dyspnoea & $-0.17(<0.01)$ & $-0.22(0.001)$ & $-0.17(0.01)$ & $-0.23(0.001)$ \\
\hline$\Delta I S W T$ & $0.09(0.22)$ & $0.23(<0.01)$ & $0.10(0.17)$ & $0.23(<0.01)$ \\
\hline$\Delta C R Q-D$ & $0.36(<0.01)$ & $0.35(<0.01)$ & $0.16(0.02)$ & $0.39(<0.01)$ \\
\hline$\Delta C R Q-F$ & $0.22(<0.01)$ & $0.21(<0.01)$ & $0.23(<0.01)$ & $0.33(<0.01)$ \\
\hline$\Delta \mathrm{CRQ}-\mathrm{E}$ & $0.41(<0.01)$ & $0.29(<0.01)$ & $0.22(<0.01)$ & $0.43(<0.01)$ \\
\hline$\triangle C R Q-M$ & $0.34(<0.01)$ & $0.23(<0.01)$ & $0.14(0.047)$ & $0.37(<0.01)$ \\
\hline$\Delta \mathrm{CRQ}-\mathrm{T}$ & $0.45(<0.01)$ & $0.36(<0.01)$ & $0.24(<0.01)$ & $0.50(<0.01)$ \\
\hline
\end{tabular}

Data are presented as $r$-value ( $p$-value). KBILD-P/B/C/T: KBILD-Psychological/Breathlessness and activities/Chest symptoms/Total; MRC: Medical Research Council; ISWT: incremental shuttle walk test; CRQ-D/F/E/M/T: Chronic Respiratory Questionnaire-Dyspnoea/Fatigue/Emotion/Mastery/Total.

score 55.9 \pm 10.7. Significant improvements in traditional pulmonary rehabilitation outcome measures and KBILD domain and total scores (KBILD-T mean score change 4.0 (95\% CI 2.3-5.7); $\mathrm{p}<0.01$ ) were observed following pulmonary rehabilitation. Effect sizes for KBILD-P, KBILD-B, KBILD-C and KBILD-T with pulmonary rehabilitation were $0.37,0.34,0.28$ and 0.39 , respectively.

The correlations between KBILD, ISWT and CRQ are reported in table 5. Similar to the ILD cohort, there were no significant correlations with $r>0.3$ between KBILD-C and any of the external anchors, and as such it was not possible to calculate an anchor-based MCID estimate for this domain.

Using linear regression and ROC plots, mean MCID estimates for KBILD in patients with IPF were: KBILD-P 5.7 points, KBILD-B 4.3 points and KBILD-T 3.9 points. Using distribution-based methods, the mean MCID estimate for KBILD-C was 9.0 points. The ranges of MCID estimates for KBILD domain and total scores are reported in table 6.

\section{Discussion}

To the best of our knowledge, this is the first study to demonstrate that KBILD is responsive to pulmonary rehabilitation in patients with ILD, including those with IPF, and to provide estimates of the MCID to intervention. Mean MCID estimates of KBILD-P, KBILD-B, KBILD-C and KBILD-T were similar for patients with ILD and IPF (ILD and IPF: KBILD-P 5.4 and 5.7 points, KBILD-B 4.4 and 4.3 points, KBILD-C 9.8 and 9.0 points, and KBILD-T 3.9 and 3.9 points, respectively). This study suggests that KBILD can be used as part of pulmonary rehabilitation assessments where it may have a role in the monitoring of disease-specific health-related quality of life, designing individually tailored pulmonary rehabilitation programmes, and measuring the impact of this intervention on health status in patients with ILD and IPF. Furthermore, it may be useful in clinical trials of pulmonary rehabilitation where a disease-specific health status pulmonary PROM is being used as an end-point.

\section{KBILD: previous studies}

KBILD was developed in response to a paucity of easy-to-use, disease-specific health status questionnaires for ILD patients [14]. It was originally developed using Rasch analysis methodology (KBILD-R) [14] and re-examined using an impact factor approach (KBILD-I) [16]. Although the content of the two

TABLE 4 Range and mean minimum clinically important difference (MCID) estimates of King's Brief Interstitial Lung Disease (KBILD) domain and total scores in patients with interstitial lung disease

Range of MCID estimates

Mean MCID estimate

\begin{tabular}{lcr}
\hline KBILD-Psychological & $4.1-6.1$ & 5.4 \\
KBILD-Breathlessness and activities & $4.0-5.1$ & 4.4 \\
KBILD-Chest symptoms & $8.4-11.2$ & 9.8 \\
KBILD-Total & $2.9-4.9$ & 3.9
\end{tabular}


TABLE 5 Correlations between change $(\Delta)$ in King's Brief Interstitial Lung Disease (KBILD) and change in other variables with pulmonary rehabilitation in patients with idiopathic pulmonary fibrosis

\begin{tabular}{lcccc} 
& $\Delta$ KBILD-P & $\Delta$ KBILD-B & $\Delta$ KBILD-C & $\Delta$ KBILD-T \\
\hline$\Delta$ MRC Dyspnoea & $-0.23(0.007)$ & $-0.26(0.01)$ & $-0.29(<0.01)$ & $-0.29(<0.01)$ \\
$\Delta$ ISWT & $0.29(<0.01)$ & $0.31(<0.01)$ & $0.11(0.26)$ & $0.29(<0.01)$ \\
$\Delta$ CRQ-D & $0.44(<0.01)$ & $0.37(<0.01)$ & $0.26(<0.01)$ & $0.46(<0.01)$ \\
$\Delta$ CRQ-F & $0.38(<0.01)$ & $0.25(0.01)$ & $0.22(0.03)$ & $0.39(<0.01)$ \\
$\Delta$ CRQ-E & $0.41 \mid<0.01)$ & $0.29(<0.01)$ & $0.18(0.06)$ & $0.39(<0.01)$ \\
$\Delta$ CRQ-M & $0.45 \mid<0.01)$ & $0.26(<0.01)$ & $0.20(0.04)$ & $0.43(<0.01)$ \\
$\Delta$ CRQ-T & $0.54(<0.01)$ & $0.28(<0.01)$ & $0.27(<0.01)$ & $0.54(<0.01)$ \\
\hline
\end{tabular}

Data are presented as $r$-value ( $p$-value). KBILD-P/B/C/T: KBILD-Psychological/Breathlessness and activities/Chest symptoms/Total; MRC: Medical Research Council; ISWT: incremental shuttle walk test; CRQ-D/F/E/M/T: Chronic Respiratory Questionnaire-Dyspnoea/Fatigue/Emotion/Mastery/Total.

questionnaires varies slightly, both consist of 15 items with three domains and a total score, and both yield similar results $[14,16]$. KBILD-R was used in this study as KBILD-I has not been released for use.

KBILD has been shown to correlate with lung function indices and health-related quality of life questionnaires (FVC \% pred $\mathrm{r}=0.38-0.51$, diffusing capacity of the lung for carbon monoxide \% pred $\mathrm{r}=0.42-0.52$, SGRQ $\mathrm{r}=-0.59--0.89$ and SF-36 $\mathrm{r}=0.33-0.70$ ) [14], to be reproducible (intraclass correlation coefficient $0.86-0.92$ ) [14], and to be responsive to ambulatory oxygen [3] and longitudinal change [15].

KBILD was the primary end-point in a crossover randomised controlled trial examining the effects of 2 weeks of ambulatory oxygen on health-related quality of life in 76 patients with fibrotic ILD (58\% IPF, $69 \%$ male with mean \pm SD age $68 \pm 10$ years, FVC $73 \pm 19 \%$ predicted and KBILD-T score $50.5 \pm 11.2$ ) [3]. Following the intervention, there was a significant improvement in KBILD domain and total scores with ambulatory oxygen compared with placebo air (mean score change in KBILD-T 3.7 (95\% CI 1.8-5.6); $\mathrm{p}<0.0001$ ) [3]. This cohort had similar baseline characteristics and response to intervention as the patients in our study.

Similarly, PATel et al. [15] evaluated the responsiveness of KBILD over a mean of 9 months in 57 patients with ILD (17\% IPF, 23\% male with mean \pm SD age $62 \pm 11$ years, FVC $80 \pm 25 \%$ predicted and KBILD-T score $60 \pm 23$ ) and provided MCID estimates. Regarding change in KBILD-T, a total of $38 \%$ of patients deteriorated, 25\% improved and 37\% remained the same, but the mean (95\% CI) change in KBILD-T was not reported [15]. Using anchor- and distribution-based methods the mean (range) MCID estimate for KBILD-T was 8 (6-10) points [15].

The MCID estimates of our study, excluding those of KBILD-C, contrast with those of PATEL et al. [15]. Regarding KBILD-C, the MCID estimates in our study were comparable to those reported by PATEL et al. [15] and may be explained by the use of distribution-based approaches. In contrast, the MCID estimates of the other domain and total scores were lower in our study. Several reasons may explain this variation. First, there were differences in the cohort characteristics and proportion of disease types between the studies, which may have influenced the MCID estimates. Our cohort had a greater proportion of male and IPF patients, who were older with greater lung function deficit. Second, our study had a larger sample size ( $\mathrm{n}=209$ in our study versus $\mathrm{n}=57$ in PATEL et al. [15]), which would have increased the statistical power to provide a more precise MCID estimate. Third, whereas PATEL et al. [15] looked at longitudinal change over

TABLE 6 Range and mean minimum clinically important difference (MCID) estimates of King's Brief Interstitial Lung Disease (KBILD) domain and total scores in patients with idiopathic pulmonary fibrosis

Range of MCID estimates

Mean MCID estimate

$\begin{array}{lcr}\text { KBILD-Psychological } & 4.2-7.0 & 5.7 \\ \text { KBILD-Breathlessness and activities } & 3.6-4.6 & 4.3 \\ \text { KBILD-Chest symptoms } & 7.7-10.3 & 9.0 \\ \text { KBILD-Total } & 2.6-4.4 & 3.9\end{array}$


9 months, our study examined the response of KBILD to an intervention, i.e. pulmonary rehabilitation. Finally, whereas we used a health-related quality of life questionnaire with similar construct to KBILD as our external anchor, the previous study utilised FVC and a global rating scale. FVC was not used as an external anchor in our study because it does not change with pulmonary rehabilitation, whereas health status was expected to improve. As such, change in FVC \% pred would most likely not meet our criteria for a valid external anchor. In addition, we did not use a global rating scale to determine the MCID because it lacks objectivity. The presence of an intervention, timescale, the choice of external anchor and the direction of change are all plausible factors that might influence the MCID estimate.

\section{Significance of findings}

PROMs aim to "directly report the status of a patient's health condition without the interpretation of a patient's response by a clinician or anybody else" [28]. PROMs are particularly relevant in clinical care as they can highlight the impact of the disease on the patient, enabling the monitoring of health-related quality of life and tailoring of patient care. Additionally, in clinical trials PROMs may capture perceived treatment effects not detected by other outcome measures, e.g. biomarkers of disease [29]. They are also likely to become established as important secondary end-points in future trials [30] to ensure patients' perspectives are considered [31] and because research funding organisations have started to place a stronger emphasis on meaningful impact for patients [30].

The PROMs most frequently used to measure health-related quality of life in ILD include a mixture of generic, respiratory and IPF-specific tools, many of which have been designed for or adapted from other chronic respiratory diseases. Additionally, the validity, responsiveness, MCID and predictive capacity of these questionnaires in ILD patients remain unknown in the majority of cases. Furthermore, pulmonary rehabilitation programmes are typically designed for COPD patients, are largely generic and are not designed specifically for ILD patients. Accordingly, PROMS that are not ILD-specific, such as CRQ [13], COPD Assessment Test [25] or Clinical COPD Questionnaire [27], are currently being used in clinical practice.

\section{Strengths}

This study, the largest pulmonary rehabilitation study involving ILD patients, provides new knowledge on the psychometric properties of KBILD in ILD and IPF by demonstrating its responsiveness to an intervention and providing MCID estimates. The capacity of an outcome measure to detect improvement is an important aspect of concurrent validity and is necessary for data interpretation in both clinical and research settings [17]. This is facilitated by the MCID, which enables the assessor to understand the clinical significance of response data and forms an important part of the evidence required by regulatory agencies for approval for use in clinical trials [32]. These properties are essential traits in an outcome tool and accordingly KBILD has potential as a measure of disease-specific health-related quality of life in the pulmonary rehabilitation setting in ILD and IPF. We used CRQ, a measure of health-related quality of life, as an external anchor. Although it was not developed specifically for ILD patients, it measures a similar construct to KBILD which may influence the accuracy of the KBILD MCID estimates. Furthermore, this study provides 22 and 26 consistent MCID estimates of KBILD domain and total scores in patients with ILD and IPF, respectively. We used multiple anchor- or distribution-based methods to calculate MCID estimates as there is no consensus on the methodology on how to perform this type of analysis [17]. Distribution-based techniques are an indirect way of estimating MCID that do not consider patients' experiences. Instead, the change in the outcome of interest is based on a form of statistical variability, e.g. standard deviation [17], which may vary depending on patient ability or baseline measurements [33]. Anchor-based approaches account for the clinical significance of the intervention, and are considered clinically robust and meaningful, but a suitable external anchor that correlates significantly with the outcome measure of interest is required [17]. REvicKI et al. [17] recommended that a correlation coefficient of $r>0.3$ is sufficient. As KBILD is a measure of health-related quality of life and accordingly captures multisystem properties, it is unlikely that a single anchor would be sufficient to estimate the MCID [34]. Therefore, use of multiple external anchors as well as different anchor- or distribution-based approaches used in this study provides a degree of reassurance on its validity.

\section{Limitations}

There are some limitations to this study. First, the study participants were symptomatic outpatients recruited from a pulmonary rehabilitation programme at the Royal Brompton and Harefield NHS Foundation Trust, a specialist, cardiorespiratory, tertiary care centre. Therefore, the data need to be corroborated in other settings and ILD populations (e.g. more symptomatic patients managed in the acute hospital setting). Second, the CRQ-Dyspnoea domain requires patients to rate how breathless they become doing five activities of their choice. A criticism of CRQ is that patients' activity choice may change over 
time. In this study, we ensured the activities selected in the CRQ-Dyspnoea domain in the pre-pulmonary rehabilitation assessment were kept the same for the post-pulmonary rehabilitation assessment. Third, despite demonstrating significant improvements with pulmonary rehabilitation, it was not possible to provide anchor-based MCID estimates for KBILD-C. This may have occurred because the external anchors did not capture the construct tested by this domain. Furthermore, the KBILD MCID may have been overestimated because it was calculated using distribution-based methods. These methods can produce estimates higher than the considered MCID [17]. Finally, few patients reported that they deteriorated with pulmonary rehabilitation; accordingly, these data estimate the MCID for improvement only. Further studies are required to assess whether patients perceive deterioration differently to the size of improvement in this context.

In summary, KBILD is responsive to pulmonary rehabilitation in patients with ILD, including those with IPF, with a mean MCID estimate of 3.9 points for KBILD-T.

Acknowledgements: We would like to express our gratitude to the patients who participated in this research and to the staff of Harefield Pulmonary Rehabilitation Unit (Harefield, UK) for their role in delivering the interventions and help with data collection.

Author contributions: Concept and design of study: W.D-C. Man, M. Maddocks, T.M. Maher and C.M. Nolan. Acquisition of data: C.M. Nolan, S.E. Jones, S. Patel and R.E. Barker. Analysis of data: C.M. Nolan, M. Maddocks and W.D-C. Man. Drafting of manuscript: C.M. Nolan, M. Maddocks, S.S. Birring, T.M. Maher and W.D-C. Man. Revision of manuscript critically for important intellectual content: all authors. Approval of final manuscript: all authors.

Conflict of interest: C.M. Nolan has nothing to disclose. S.S. Birring reports fees paid to King's College Hospital for use of KBILD from Roche, Boehringer Ingelheim and Galapagos, outside the submitted work. M. Maddocks reports grants (CDF-2017-10-009 and HSDR 16/02/18) from NIHR, outside the submitted work. T.M. Maher has, via his institution, received industry-academic funding from GlaxoSmithKline R\&D and UCB, and has received consultancy or speakers fees from Apellis, AstraZeneca, aTyr Pharma, Bayer, Biogen Idec, Boehringer Ingelheim, Celgene, Galapagos, GlaxoSmithKline R\&D, Indalo, Pliant, ProMetic, Roche, Samumed and UCB. S. Patel has nothing to disclose. R.E. Barker has nothing to disclose. S.E. Jones has nothing to disclose. J.A. Walsh has nothing to disclose. S.C. Wynne has nothing to disclose. P.M. George reports personal fees for lecturing and nonfinancial support for meeting attendance from Boehringer Ingelheim and Roche Pharmaceuticals, personal fees for lecturing from Teva, outside the submitted work. W.D-C. Man reports grants from National Institute for Health Research, during the conduct of the study; grants from Pfizer, nonfinancial support from GlaxoSmithKline, personal fees from Mundipharma and Novartis, outside the submitted work.

Support statement: C.M. Nolan is funded by a National Institute for Health Research (NIHR) Doctoral Research Fellowship (DRF-2014-084) for this research project. This publication presents independent research. The views expressed are those of the author(s) and not necessarily those of the NHS, the NIHR or the Dept of Health and Social Care. Funding information for this article has been deposited with the Crossref Funder Registry.

\section{References}

1 Swigris J, Kuschner W, Jacobs S, et al. Health-related quality of life in patients with idiopathic pulmonary fibrosis: a systematic review. Thorax 2005; 60: 588-594.

2 Wells A, Hirani N. Interstitial lung disease guideline. Thorax 2008; 63: Suppl. 5, v1-v58.

3 Visca D, Mori L, Tsipouri V, et al. Effect of ambulatory oxygen on quality of life for patients with fibrotic lung disease (AmbOx): a prospective, open-label, mixed-method, crossover randomised controlled trial. Lancet Respir Med 2018; 6: 759-770.

4 National Institute for Health Care and Excellence. Idiopathic pulmonary fibrosis in adults: diagnosis and management. 2013. www.nice.org.uk/guidance/cg163 Date last updated: May 2017. Date last accessed: January 10, 2019.

5 Dowman L, Hill CJ, Holland AE. Pulmonary rehabilitation for interstitial lung disease. Cochrane Database Syst Rev 2014; 10: CD006322.

6 Dheda K, Lalloo U, Cassim B, et al. Experience with azathioprine in systemic sclerosis associated with interstitial lung disease. Clin Rheumatol 2004; 23: 306-309.

7 Huppmann P, Sczepanski B, Boensch M, et al. Effects of inpatient pulmonary rehabilitation in patients with interstitial lung disease. Eur Respir J 2013; 42: 444-453.

8 King TE Jr, Bradford WZ, Castro-Bernardini S, et al. A phase 3 trial of pirfenidone in patients with idiopathic pulmonary fibrosis. N Engl J Med 2014; 370: 2083-2092.

9 Nishiyama O, Kondoh Y, Kimura T, et al. Effects of pulmonary rehabilitation in patients with idiopathic pulmonary fibrosis. Respirology 2008; 13: 394-399.

10 Perez-Bogerd S, Wuyts W, Barbier V, et al. Short and long-term effects of pulmonary rehabilitation in interstitial lung diseases: a randomised controlled trial. Respir Res 2018; 19: 182.

11 Richeldi L, du Bois RM, Raghu G, et al. Efficacy and safety of nintedanib in idiopathic pulmonary fibrosis. $N$ Engl J Med 2014; 370: 2071-2082.

12 Dowman LM, McDonald CF, Hill CJ, et al. The evidence of benefits of exercise training in interstitial lung disease: a randomised controlled trial. Thorax 2017; 72: 610-619.

13 Holland AE, Hill CJ, Conron M, et al. Short term improvement in exercise capacity and symptoms following exercise training in interstitial lung disease. Thorax 2008; 63: 549-554.

14 Patel AS, Siegert RJ, Brignall K, et al. The development and validation of the King's Brief Interstitial Lung Disease (K-BILD) health status questionnaire. Thorax 2012; 67: 804-810. 
Patel AS, Siegert RJ, Keir GJ, et al. The minimal important difference of the King's Brief Interstitial Lung Disease Questionnaire (K-BILD) and forced vital capacity in interstitial lung disease. Respir Med 2013; 107: 1438-1443.

16 Patel AS, Siegert RJ, Bajwah S, et al. Rasch analysis and impact factor methods both yield valid and comparable measures of health status in interstitial lung disease. J Clin Epidemiol 2015; 68: 1019-1027.

17 Revicki D, Hays RD, Cella D, et al. Recommended methods for determining responsiveness and minimally important differences for patient-reported outcomes. J Clin Epidemiol 2008; 61: 102-109.

18 Maddocks M, Kon SS, Canavan JL, et al. Physical frailty and pulmonary rehabilitation in COPD: a prospective cohort study. Thorax 2016; 71: 988-995.

19 British Thoracic Society. Quality standards for pulmonary rehabilitation. 2014. https://www.brit-thoracic.org.uk/ quality-improvement/quality-standards/pulmonary-rehabilitation Date last accessed: June 8, 2019.

20 Nolan CM, Maddocks M, Canavan JL, et al. Pedometer step count targets during pulmonary rehabilitation in chronic obstructive pulmonary disease. A randomized controlled trial. Am J Respir Crit Care Med 2017; 195: 1344-1352.

21 Quanjer PH, Tammeling G, Cotes J, et al. Lung volumes and forced ventilatory flows. Eur Respir J 1993; 6: Suppl. $16,5-40$.

22 Bestall JC, Paul EA, Garrod R, et al. Usefulness of the Medical Research Council (MRC) dyspnoea scale as a measure of disability in patients with chronic obstructive pulmonary disease. Thorax 1999; 54: 581-586.

23 Nolan CM, Delogu V, Maddocks M, et al. Validity, responsiveness and minimum clinically important difference of the incremental shuttle walk in idiopathic pulmonary fibrosis: a prospective study. Thorax 2018; 73: 680-682.

24 Williams JE, Singh SJ, Sewell L, et al. Development of a self-reported Chronic Respiratory Questionnaire (CRQ-SR). Thorax 2001; 56: 954-959.

25 Kon SS, Canavan JL, Jones SE, et al. Minimum clinically important difference for the COPD Assessment Test: a prospective analysis. Lancet Respir Med 2014; 2: 195-203.

26 Jaeschke R, Singer J, Guyatt GH. Measurement of health status: ascertaining the minimal clinically important difference. Control Clin Trials 1989; 10: 407-415.

27 Kon SS, Dilaver D, Mittal M, et al. The Clinical COPD Questionnaire: response to pulmonary rehabilitation and minimal clinically important difference. Thorax 2014; 69: 793-798.

28 Raghu G, Collard HR, Anstrom KJ, et al. Idiopathic pulmonary fibrosis: clinically meaningful primary endpoints in phase 3 clinical trials. Am J Respir Crit Care Med 2012; 185: 1044-1048.

29 Swigris JJ, Fairclough D. Patient-reported outcomes in idiopathic pulmonary fibrosis research. Chest 2012; 142: 291-297.

30 Maher TM. Idiopathic pulmonary fibrosis. In: Kolb M, Vogelmeier CF, eds. Outcomes in Clinical Trials (ERS Monograph). Sheffield, European Respiratory Society, 2013; pp. 37-53.

31 Russell A-M, Sprangers MA, Wibberley S, et al. The need for patient-centred clinical research in idiopathic pulmonary fibrosis. BMC Med 2015; 13: 240-247.

32 Committee for Medicinal Products for Human Use. Reflection paper on the regulatory guidance for the use of health-related quality of life (HRQL) measures in the evaluation of medicinal products. 2005. www.ispor.org/ workpaper/emea-hrql-guidance.pdf Date last accessed: July 15, 2016.

33 Stratford PW, Binkley JM, Riddle DL, et al. Sensitivity to change of the Roland-Morris back pain questionnaire: part 1. Phys Ther 1998; 78: 1186-1196.

34 Guyatt GH, Osoba D, Wu AW, et al. Methods to explain the clinical significance of health status measures. Mayo Clin Proc 2002; 77: 371-383. 